\title{
Does Technology Enabled Design-Thinking Influence Digital Innovation? An Innovation Affordance Perspective
}

\author{
Anuragini Shirish \\ LITEM, Univ Evry, IMT-BS \\ Université Paris-Saclay \\ anuragini.shirish@imt-bs.eu
}

\author{
Imed Boughzala \\ LITEM, Univ Evry, IMT-BS \\ Université Paris-Saclay \\ imed.boughzala@imt-bs.eu
}

\author{
Shirish C. Srivastava \\ IS\&OM Department \\ HEC Paris \\ srivastava@hec.fr
}

\begin{abstract}
Though prior research recognizes the vital role of the 'innovation agents' in effectuating digital innovation, little attention has been given to examine the role of 'innovation affordances'. Drawing on digital innovation literature, we conceptualize the influence of both - 'innovation agent' and 'innovation affordance' factors on the extent of digital innovation. We then test the theorized model via a quasi-experimental study, where the extent of digital innovation from a technology enabled design-thinking creative process is examined. Though the results from our study demonstrate the salience of both 'innovation agent' and 'innovation affordance' factors, the latter operationalized through technology enabled design-thinking process, the construct for which is developed in our study, has a stronger influence on digital innovation. Our research emphasizes the need for having a well-structured technology enabled creative process to actualize the innovation affordances. The findings have significant theoretical and practical implications.
\end{abstract}

\section{Introduction}

Digital innovation, which is defined as the use of technology for innovation, is at the heart of today's economy. Organizations, nations, and societies are leveraging digital capabilities and technologies to stimulate and create value for different stakeholder groups through innovation. Though, businesses and societies have realized the importance of digital innovations [1][2][3][4][5], theoretical deliberations devoted to understanding the modalities for fostering such innovations are limited [6]. Thus, research that focuses on theorizing and examining the factors facilitating digital innovation will be of value to both theory and practice.

Prior digital innovation literature has identified several factors imperative for fostering innovation. These factors can be classified into two major categories - (1) 'innovation agent factors', i.e. the aspects related to the capabilities, skills, and knowledge of the human agents involved in the creative process, and (2) 'innovation affordance factors' related to the interaction and use of technology by human agents for creative innovation process [7][8]. Traditionally, innovation has been linked to the creative ability of the individuals involved in the innovative process. Such innovation agent abilities have been shown to transcend their general attributes such as intelligence or personality traits to include domain and task specific attributes, which have been shown to influence innovation outcomes [9][10]. In our study, we classify such factors as 'innovation agent factors'. On the other hand, in our research context, we broadly describe 'innovation affordance factors' as the processes surrounding the innovation effort through the use of technology.

Lately, digital innovation researchers have pointed to the key role of a structured creative innovation process enabled by information and communication technologies (ICTs). Studies have investigated the role of creativity support systems in enhancing the level of innovation by stimulating and documenting creative processes [11][12]. Among the various structured innovation processes, the design-thinking approach proposed by Hasso-Plattner-Institute of Design at Stanford University has gained wide popularity amongst innovation practitioners to find a creative solution to a 
problem and is considered as one of the effective creative processes [13][14][15]. Hence, we focus on design-thinking approach as the innovation affordance factor in terms of a structured innovation process for actualizing the innovation by the human agents. The ICT enabled design-thinking process [16], depicted through a sequence of five activities - (1) empathize (data collection about the problem), define (data synthesis to gain a refined understanding of the problem), ideate (suggest ideas for solving the problem), prototype (develop tangible representations of the ideas for solving the problem), and test (the problem solution with potential users) is one of the popular methods employed in the context of digital innovations [14].

The two questions that we examine in this research are:

$R Q$ 1: What is the influence of 'innovation agent factors' on digital innovation?

$R Q$ 2: What is the influence of 'innovation affordance factors' on digital innovation?

The primary contribution of the study is to go beyond the innovation agent factors in understanding the process of digital innovation. Specifically, we unearth the key role of ICT enabled design-thinking process as an actualized innovation affordance mechanism for effectuating digital innovations [17] and thus answer to the calls for integrating creativity and digital innovation literature [1]. In addition to highlighting the need for conceptualizing innovation affordances rather than just thinking of technology and the users of technology, our study validates the efficacy of ICT enabled design-thinking approach for creative innovation process, thereby contributing to the growing interactional or ecological perspective on creativity and digital innovation [8].

The rest of the paper is organized as follows. First, we describe the theoretical arguments leading to our research hypotheses and model. Next, we describe the details of the quasi-experimental method for validating the hypothesized model by first developing the ICTenabled design thinking process construct. Finally, we end the paper with a set of theoretical and practical implications.

\section{Theory and Hypotheses \\ 2.1 Innovation agent factors and digital innovation}

In our research, we consider two innovation agent factors for facilitating digital innovation - the first one is related to the human agent's cognitive aspects, namely, innovation agent's creative self-efficacy and second one is related to the human agent's affective aspects towards the use of technology, namely, innovation agent's affect towards ICT.

Creativity theorists have flagged the importance of examining agent's self-perceptions about their own creative behaviors and capabilities (e.g., [18][19]). Past literature on creativity has emphasized the need to examine the individual's capabilities in orchestrating creative processes and behaviors [18]. Prior literature has also indicated the key role of self-efficacy in the processes involving self-regulation [20][21]. In fact, domain specific self-efficacy has been found to have a stronger influence on outcomes as opposed to a general self-efficacy measure [22][23]. Consequently, in our research we theorize the key role of creative selfefficacy in our research model. Tierney and Farmer [24][25] observed that creative self-efficacy is a significant predictor of an individual's creative performance. Creative self-efficacy is the belief that one has the requisite knowledge and skills to produce creative outcomes [26][27][24][25], and is a key driver for individual creativity which is quintessential for digital innovation [1]. Hence, based on the past studies, we argue that creative self-efficacy should positively influence digital innovation.

H1a: Innovation agent's creative self-efficacy positively influences digital innovation.

Information systems literature has highlighted that a positive affect towards technology results in better mobilization of technology for specific task situations. Affect towards technology is taken as one of the domain specific capabilities of the individual and is expected to positively impact digital innovations [10]. Prior studies have also found that affect, in general, guides congruent behavioral responses [28][29][30]. Behavioral affective association model predicts that positive/negative affective associations influence not only the cognitive beliefs and behavioral responses of the individuals but also have an impact on their final decisions and outcomes [31]. Affect has also been viewed as one of the dimensions of technology attitude [19] and affect towards ICT use is specific to the of technology use context [32]. Based on prior studies, an innovative 
agent's affective experience should influence creativityrelevant motivational processes, which in turn should influence the extent of their digital innovation $[33][34][35][36][37]$. We believe that innovative agent's affective disposition towards ICT will be crucial in understanding technology facilitated creative intervention [38]. Thus, human agent's affect towards technology would determine the agent's innovative behavior leading to digital innovations.

H1b: Innovation agent's affect towards technology positively influences digital innovation.

\subsection{Innovation affordance factors and digital innovation}

Technology affordance refers to "an action potential, that is, to what an individual or organization with a particular purpose can do with a technology or information system" [39]. Technology is known to facilitate creativity in several possible ways as it is viewed as institutional support mechanism for creative process engagement [40]. Calls for empirically examining how technology is imbricated in specific creative processes continues to attract the attention of researchers [41][7].

We argue that the affordances of ICT enabled innovation processes should impact digital innovations. The mangling of structured processes with technology through reciprocal and emergent intertwining of human and technical practices can explain the extent of digital innovation [42] and hence innovation affordances has been proposed as a useful lens to study digital innovations in action [3][43][6]. Specifically, we leverage the works of Lubart [40] to hypothesize the relationship between innovation affordances and digital innovation.

In his seminal work, Lubart [40] described the key role of digital technologies in facilitating creative work through various mechanisms such as enhancing the communication between individuals collaborating on creative projects, using creativity enhancement techniques, and integrating human-computer interactions during the idea production stage. In line with his findings, we believe that information communication technology (ICTs) should facilitate the use of design-thinking creative processes that focuses on collecting user-needs, ideating, experimenting, generating prototype models, gathering feedback, and eventually designing/redesigning innovations. The presence and non-restricted use of ICTs should lead to open and flexible innovation affordances as they can be viewed to support the convergence of ideas and allow for generative experimentation - supporting both the generative and exploratory phases of design-thinking process.

ICTs can afford a viable foundation to understand the potential problems of users in depth as they permit easy collection of user data. Moreover, ICTs would also facilitate efficient data synthesis and analysis which clearly is superior to manual processes. Thus, ICTs can help innovation agents to better empathize and define the problem that requires an innovative solution. In a similar vein, ICTs can also be useful during the testing phase of design-thinking for obtaining user feedbacks and also for capturing the digital usage footprints of the innovation agents. This information can be used to tweak the innovative process for better results. ICTs also afford better creative communication management amongst the innovation agents involved in a project [40] which we believe is crucial for defining and ideating about the intended digital innovation. Defining and ideating stages of the design-thinking process require close collaboration wherein ICTs can act as a complement to face-to-face communication. Moreover, in the case of digital innovation, the innovative agents may also see affordances in use of ICTs to express their creative acts through integrated human-computer cooperation during idea production [40]. ICTs allow to implicitly represent and manipulate ideas - such an affordance is useful during the ideation and prototyping phases of design-thinking.

Notwithstanding the key role of technology affordances for design-thinking creative process, Oldham and Silva [44], in their recent work, enumerate three supportive institutional conditions for facilitating innovation that can be bolstered by the availability and use of ICTs- (1) access to new and diverse information, (2) engagement in the work roles, and (3) socioemotional and instrumental support for individuals involved in creative tasks, which includes mustering support for their ideas and implementation [44]. Therefore, technology enabled creative process support perceptions are expected to increase the individual's sense of control, which can help to boost the agent's motivation, thereby contributing positively to digital innovations [45]. 
Consistent with the ecological or the interactional perspective on creativity [7] [8], we believe that despite the importance of innovation agent factors, the innovation process factors will play a crucial role in explaining digital innovations. It is known the efficacious individuals seek out opportunities and resources available in the social context to further their goals and aspirations [46]. In summary, structured creative process is known to positively influence innovation as it aids in the planning and the execution of innovations (see for example [47][48][49][50]). ICT use in the structured process of design-thinking can increase innovation agent's control over the execution of the creative process which in turn will enhance digital innovations. Further, the use of ICTs for creative process would allow the innovation agent to appropriate both the convergent and generative affordances for digital innovation enactment [4]. Hence, we argue that the innovation affordance perceptions should positively influence digital innovation of the innovating agent over and above the innovation agent factors. Thus, we posit:

H2: ICT enabled design-thinking creative process positively influences digital innovation.

\section{Method \\ 3.1 Data Collection}

Quasi-experimental methodology was adopted where data was collected through a two-wave survey from participants in a natural academic setting. The respondents were first year graduate students majoring either in engineering or management disciplines. The participants had enrolled in a joint collaborative academic program between a business school and an engineering school in France. The participants from both the schools, signed up for a week long graded collaborative academic program where the objective was to work on a collaborative digital social innovation project focused on alleviating societal problems using digital innovation. The participants were introduced to the concept of design-thinking as part of their creativity training program on the first day of their program and were encouraged to use this structured innovation process for their projects. They worked as a team for a week and on the last day, they had to present their proof of concept through a 3 minute video teaser and create a website for their new venture detailing the elements of their digital social innovation. They were also asked to provide a 2-page synthesis of their innovation as a part of their grading process on the last day of the program. The individual academic scores were provided based on the peer evaluation. A panel of jury evaluated the team's final digital innovation project presentation. This score become part of their academic grades. Approximately 400 students participated in this week-long program.

The research data was collected from each of the team members in two study waves in the form of surveys - first, at the start of the week-long program and second, at the end of the study project. 178 students responded to both the surveys. Data on creative selfefficacy, affect towards ICT use and demographics were collected during the first wave, and for ICT enabled design-thinking creative process and ICT enabled digital innovation during the second wave. Validated constructs from prior studies where psychometric properties have already been established, were adapted and used in this study. We used 3 item scales for affect towards ICTs use from [32], it has items such as "using ICTs makes work more interesting". We adapted 6 item scales for measuring creativity self-efficacy from [51]. Example items include; "I am confident about my ability to solve problems creatively"; "I feel that I am good at generating novel ideas". Project complexity construct was measured using [52]. We asked questions on general complexity levels of their project, use of nonroutine methodology and use of complex development processes in their projects. Digital innovation was measured using 3 item scales adapted from [53]. They were "ICTs help me to try out innovative ideas"; "ICTs help me to come up with new ideas relating to my team tasks"; "ICTs help me to identify innovative ways of doing my team tasks". All constructs except, ICT enabled design-thinking creative process have been modeled using reflective indicators. The new construct called ICT enabled design-thinking creative process was developed during the study. We followed all the rigorous procedures for new scale development to validate the new scale for "ICT enabled design-thinking process" which is provided in Appendix 1. Because the dependent variables may be influenced by factors other than those in the hypothesized model, we incorporated suitable controls in our research model. Following similar previous research two kinds of control variables were used -individual level attribute (gender) and the project level attribute (project complexity). Because the study relies on natural academic setting the innovation 
reward-recognition objective climate is assumed to be uniform for all participants in the study.

\subsection{Data Analysis, Results, and Discussion}

Among the 178 respondents, the age of the respondents ranged between 22 to 26 years. For the purposes of the data analysis, we used Partial Least Squares (PLS), a latent structural equation modeling technique, as implemented in Smart PLS 3.0, which utilizes a component-based path modeling application [54]. PLS avoids the two major problems of inadmissible solutions and factor indeterminacy and is thus appropriate for analyzing complex models with latent variables [55][56].

Following the recommended two-stage analytical procedure [57], the first stage of data analysis evaluates the measurement properties of the constructs, while the second stage examines the structural relationships. First, the measurement model assessment for the two types of variables (reflective and formative measures) used in the model was undertaken.

\subsubsection{Evaluating Measurement Model for} Reflective Constructs

We tested three types of validity: content validity, convergent validity, and discriminant validity. Content validity assesses whether the chosen measures appropriately capture the full domain of the construct [58]. We examined content validity by checking for consistency between the measurement items and the existing literature. This was done at the stage of designing the questionnaire.

Convergent validity checks that the indicators for a construct are more correlated with one another than with the indicators of another construct [59]. We tested the measurement model with digital innovation measured as ICT enabled digital innovation. Factor analysis shows strong correlation between each of the items and their corresponding construct. This demonstrates convergent validity. We further tested convergent validity by examining the composite reliability (CR) and average variance extracted (AVE: the ratio of the construct variance to the total variance among indicators) for the indicators [57] 0.70 is the suggested CR threshold for reliable measurement [60]. As can be seen in Table 1, the CR values ranged from 0.85 to 0.90 . For the AVE, against the recommended threshold of 0.50 [55], ranged from 0.55 to 0.76 . In addition, the high Cronbach alpha values, ranging from 0.74 to 0.84 , confirm the reliability of the scales for all the constructs.

We verified the discriminant validity of the various constructs by checking the square root of the average variance extracted, as recommended by [55]. The values of the square root of the AVE (shown on the diagonal in Table 2) are all greater than the corresponding interconstruct correlations (the off-diagonal entries in Appendix 2), exhibiting satisfactory discriminant validity. We also checked the cross-loadings of the items on other constructs, which are quite low indicating discriminant validity (Table 4).

Table 1: Measurement model for assessment for reflective constructs

\begin{tabular}{|l|r|r|r|r|}
\hline & $\begin{array}{c}\text { Cronbach's } \\
\text { Alpha }\end{array}$ & \multicolumn{1}{c}{$\begin{array}{c}\text { Rho } \\
\text { A }\end{array}$} & $\begin{array}{c}\text { Composite } \\
\text { Reliability }\end{array}$ & $\begin{array}{c}\text { Average } \\
\text { Variance } \\
\text { Extracted } \\
\text { (AVE) }\end{array}$ \\
\hline ATU & 0.81 & 0.81 & 0.89 & 0.72 \\
\hline CSEFF & 0.84 & 0.86 & 0.88 & 0.55 \\
\hline DINV & 0.85 & 0.85 & 0.91 & 0.77 \\
\hline PCOMP & 0.74 & 0.78 & 0.85 & 0.65 \\
\hline
\end{tabular}

Note: ATU- Affect towards technology; CSEFF- Creative Self efficacy; DINV- ICT enabled innovation; PCOMPProject Complexity, Gender is a single indicator variable

Table 2: Fornell-Larcker criterion

\begin{tabular}{|l|r|r|r|r|}
\hline & ATU & CSEFF & DINV & GEN \\
\hline ATU & 0.85 & & & \\
\hline CSEFF & 0.20 & 0.74 & & \\
\hline DINV & 0.34 & 0.24 & 0.88 & \\
\hline GEN & -0.04 & 0.17 & -0.05 & 1.00 \\
\hline PCOMP & 0.17 & 0.12 & 0.25 & 0.01 \\
\hline
\end{tabular}

Note: ATU- Affect towards technology; CSEFF- Creative Self efficacy; DINV- ICT enabled innovation; GENGender; PCOMP- Project Complexity.

Table 3: Crossloadings

\begin{tabular}{|l|r|r|r|r|r|}
\hline & ATU & CSEFF & DINV & GEN & PCOMP \\
\hline ATU1 & $\mathbf{0 . 8 7}$ & 0.15 & 0.31 & -0.01 & 0.20 \\
\hline ATU2 & $\mathbf{0 . 8 8}$ & 0.20 & 0.28 & -0.03 & 0.19 \\
\hline ATU3 & $\mathbf{0 . 7 9}$ & 0.16 & 0.27 & -0.08 & 0.11 \\
\hline CSEFF1 & 0.23 & $\mathbf{0 . 7 1}$ & 0.18 & 0.216 & 0.050 \\
\hline CSEFF2 & 0.09 & $\mathbf{0 . 7 9}$ & 0.16 & 0.203 & 0.14 \\
\hline CSEFF3 & 0.05 & $\mathbf{0 . 6 9}$ & 0.17 & 0.019 & 0.08 \\
\hline CSEFF4 & 0.07 & $\mathbf{0 . 7 9}$ & 0.11 & 0.168 & 0.16 \\
\hline
\end{tabular}




\begin{tabular}{|l|r|r|r|r|r|}
\hline CSEFF5 & 0.20 & $\mathbf{0 . 7 5}$ & 0.25 & 0.045 & 0.14 \\
\hline CSEFF6 & 0.17 & $\mathbf{0 . 6 9}$ & 0.13 & 0.155 & -0.06 \\
\hline GENDER & -0.04 & 0.17 & -0.05 & $\mathbf{1 . 0 0 0}$ & 0.01 \\
\hline DINOV1 & 0.26 & 0.26 & $\mathbf{0 . 8 6}$ & -0.03 & 0.23 \\
\hline DINOV2 & 0.30 & 0.21 & $\mathbf{0 . 8 9}$ & -0.06 & 0.21 \\
\hline DINOV3 & 0.34 & 0.17 & $\mathbf{0 . 8 8}$ & -0.04 & 0.21 \\
\hline PCOM1 & 0.06 & 0.13 & 0.13 & 0.08 & $\mathbf{0 . 7 6}$ \\
\hline PCOM2 & 0.19 & 0.10 & 0.21 & -0.02 & $\mathbf{0 . 7 8}$ \\
\hline PCOM3 & 0.13 & 0.08 & 0.23 & -0.02 & $\mathbf{0 . 8 8}$ \\
\hline Note: ATU- Affect towards technology; CSEFF- Creative \\
Self efficacy; DINV- ICT enabled innovation; GEN- \\
Gender; PCOMP- Project Complexity. \\
\hline
\end{tabular}

\subsubsection{ICT enabled Design-thinking: Evaluation of Formative Measurement Construct}

The recommended three stage approach is prescribed for evaluating the formative measurement indicators [61]. However, before evaluating the measurement aspects for the formative construct the content validity of the construct must be established. To establish the content validity of the -ICT enabled design-thinking creative process construct, a thorough literature review was conducted with respect to different aspects of the constructs. Initial indicators were developed that can address the five stages of designthinking process widely practiced in organizations even outside of the technology sector (such as banking sector) [62][63]. Due to space constraints we do not elaborately describe the literature on design-thinking but a good overview is provided in a recent work [64]. In principle, we analyzed the content for each of the five phases. Design-thinking as such is a creative problem-solving method that can be depicted through a sequence of five activities - (1) empathize (data collection about the problem), define (data synthesis to gain a refined understanding of the problem), ideate (suggest ideas for solving the problem), prototype (develop tangible representations of the ideas for solving the problem) and test (the problem solution with potential users). Empathize, is the first stage, where the individuals collect data about the real need or the problem that requires a creative solution. The second stage is to define the problem clearly with a view to solve it. In this stage the individual needs to synthesize the gathered to gain a refined understanding of the problem. The third phase is to ideate the meaning where individuals need to suggest or invent ideas for solving the problem. The fourth stage is to prototype tangible representations of the ideas. The last stage is to test the prototype with the potential users to check if the identified creative solutions are relevant to the needs of the intended users.

In this study, we examine the process of designthinking enabled by ICT. We posit that the described five phases of the human centered design-thinking approach is pertinent for any innovative process. Thus, the concept of design-thinking is multifaceted and is formed together by all the phases and not a mere reflection of these five phases. Theoretically, these five components interact with ICT to comprise the full content of ICT enabled design-thinking creative process. We first generated 12 items that represented the five stages and then refined the list of measures using a structured process with the help of 9 innovation experts heading different innovation hubs (incubators). After finalizing the indicators for ICT enabled designthinking, to make the measure parsimonious, we used one item to represent each of the five stages of designthinking process in the conceptualized formative construct for "ICT enabled design-thinking".

Following the guidelines [61], we proceeded to evaluate the convergent validity of the formative construct. The convergent validity of the formative construct is measured by examining its correlation with an alternative measure of the construct, using reflective measures or a global single item measure [61]. If the correlation between the formative construct and the reflective construct is above 0.70 or higher then construct is said to have convergent validity [61]. Because there was no prior construct in the literature that represented design-thinking or ICT enabled designthinking we had to use a new set of indictors that reflected each of the five stages of design-thinking from the original pool of items generated using literature review that were different from the five items chosen to create the new formative construct. We then ran the redundancy test using the procedure provided by [61] The correlation between the formative ICT enabled design-thinking construct and the reflective ICT enabled design-thinking construct was 0.97 which is higher than the prescribed threshold of 0.70 . Thus, we concluded that the construct has good convergent validity.

The next stage in establishing the measurement model of the formative construct is to examine the collinearity of the indicators comprising the formative construct. It is recommended that the VIF value for each indicator be lower than 5. The VIF value of all the 
formative indicators ranged from 1.34 to 1.53 which is lower than 5; we therefore concluded there is no multicollinearity between the indicators comprising the construct.

The third stage of evaluation of the formative construct involves assessing the significance and relevance of the formative construct. The significance of the outer weights is assessed to determine if all the chosen five indicators are relevant for explaining the proposed formative construct. After running bootstrapping procedure, we found that the outer weights for the five ICT enabled design-thinking creative process items were not significant. Therefore, we proceeded to check the outer loadings as per the decision process prescribed for such analysis [61] to assess their significance. All the outer loadings of the indicators for the ICT enabled design-thinking creative process construct were greater than or equal to 0.50 and had significant ' $p$ ' values $(\mathrm{p}<0.05)$. Thus, we concluded that all the items of the newly formed construct should be retained as they are all useful in explaining the focal formative construct. After testing the measurement model for the reflective and formative constructs we proceeded to test the structural model.

\subsubsection{Structural Model Assessment to Test} the Hypothesized Relationships

The results from the structural model are indicated in Table 5 and Figure 1.

The results are presented in Table 5 as a step-wise hierarchical structural model, where in the step 1 only control variables were introduced, in step 2 we introduced innovation agent factors in addition to the control variables, and in step 3, we added the innovation affordance factor. We observe that among the control variables entered in model 1 ; gender is not significant $(\beta=-0.05, p>0.05)$ but the perception of project complexity is significantly related to digital innovation $(\beta=-0.25, p<0.01)$. In the model 2 , we note that innovation agent's creative self-efficacy is significantly related to digital innovation $(\beta=0.18, \quad p<0.05)$, supporting H1a. Similarly, affect towards ICT has a significant relationship with digital innovation $(\beta=.27$, $\mathrm{p}<0.01$ ), thereby providing support to H1b. Model 3 provides us insights on innovation affordance factor where ICT enabled design-thinking is found be significantly related to digital innovation $(\beta=0.57$, $\mathrm{p}<0.01$ ), supporting $\mathrm{H} 2$.
Table 5: Hierarchical Structural Model Results

\begin{tabular}{|c|c|c|c|}
\hline & \multicolumn{3}{|c|}{ Digital Innovation } \\
\hline & $\begin{array}{l}\text { Model 1 } \\
\text { B }\end{array}$ & $\begin{array}{l}\text { Model } 2 \\
\text { B }\end{array}$ & $\begin{array}{l}\text { Model 3 } \\
\text { B }\end{array}$ \\
\hline \multicolumn{4}{|c|}{ Control Variables } \\
\hline Gender & -0.05 & -0.07 & -0.05 \\
\hline $\begin{array}{l}\text { Project } \\
\text { Complexity } \\
\text { Perception }\end{array}$ & $0.25 * *$ & $0.18^{* *}$ & 0.04 \\
\hline \multicolumn{4}{|c|}{ Innovation Agent Variables } \\
\hline $\begin{array}{l}\text { Creative Self } \\
\text { Efficacy }\end{array}$ & & $0.18 *$ & $0.14 *$ \\
\hline $\begin{array}{l}\text { Affect towards } \\
\text { ICT use }\end{array}$ & & $0.27 * *$ & $0.17 *$ \\
\hline \multicolumn{4}{|c|}{ Innovation Affordance Variable } \\
\hline $\begin{array}{l}\text { ICT enabled } \\
\text { Design-thinking } \\
\text { Creative Process }\end{array}$ & & & $0.51 * *$ \\
\hline $\mathrm{R}^{2}$ & 0.063 & 0.182 & 0.404 \\
\hline$\Delta \mathrm{R}^{2}$ & & $0.119 * *$ & $0.222 * *$ \\
\hline
\end{tabular}

Figure 1: Results - Structural Model



For the evaluation of the predictive relevance of the structural model, the Stone and Geisser $\mathrm{Q}^{2}$ test was performed using the blindfolding procedure [65][66]. The blindfolding test, which was conducted with omission distance equals to 7 (the recommended number), revealed that all $\mathrm{Q}^{2}$ values of endogenous variable were greater than zero (digital innovation): 0.33 for model $1,0.12$ for model 2 and 0.27 for model 3 . 
Positive $\mathrm{Q}^{2}$ values provide evidence of the predictive relevance from the research sample size.

The $\mathrm{R}^{2}$ or variance explained from each model further elaborates that the control variables only explained $6.3 \%$ of the variance in digital innovation (Model 1). However, innovation agent factors together with control variables explains $18.2 \%$ of the variance in digital innovation (Model 2). Whereas innovation affordance factor of ICT enabled design-thinking process together with control variables and innovation agent factor explains $40.4 \%$ of variance in digital innovation (Model 3). Further the change in variance $\left(\Delta \mathrm{R}^{2}\right)$ from Model 2 to Model 3 is significant to the extent of $22.2 \%$ in contrast to only $11.9 \%$ change from Model 1 to Model 2. This clearly highlights the relatively greater importance of the innovation affordance factor (in the form of ICT enabled designthinking) in comparison to innovation agent factors.

\section{Implications, Limitations, and Future Work}

The study has significant theoretical and practical implications. Theoretically, the first contribution relates to the demonstration of the fact that domain specific innovation agent factors and domain specific innovation affordance factors both act as micro foundations for individual level digital innovations. These results also explain some of the under-examined aspects of innovation agent's digital innovation orchestration phenomenon [6]. Second, our study is one of the first that not only theorizes innovation affordances factors for digital innovations but also demonstrates the greater salience of innovation affordance factors in the form of ICT enabled design-thinking creative process. Through our work we thus contribute to the interactional and ecological perspective on creativity and digital innovation [7] [6]. We have conceptualized innovation affordance as an actual mangling of practices between technology and human creative process [3]. Third, our research is the first study that empirically establishes the importance of ICT enabled design-thinking creative process for digital innovation which is an important contribution to the still nascent design-thinking literature. Fourth, our study further contributes to the design-thinking literature by operationalizing the ICT enabled design-thinking creative process measure as a five item formative construct and thus enriches the rather sparse literature that links individual level creativity process engagement with digital innovation [1]. This validated scale can contribute to the stream of literature that investigates the performative aspects of design-thinking [see 64] in a natural setting. The scale can be used by future researchers to further contribute to this important research domain.

Practical implications from this work include the following. First, the results from the study direct innovation practitioners to provide digital infrastructure and facilitate their use during innovation interventions in organizations. The study also shows that the imbrication of human and material technologies can contribute to an affordance perception for creativity related tasks. Second, care should be taken to not only rely on multivariate and cognitive determinants of creativity for recruitment and selection of employees for innovative projects. From the results of the study, we see that an ecological perspective is more effective for digital innovation. Hence the managerial focus should be on providing a supportive process based environment that lays down a framework for the workers to enable creative output. ICT enabled design-thinking can be one of the structured approaches that can be effective for fostering innovation. Third, human resource practitioners should take into consideration the role of domain specific and task specific innovation agent factors such as 'creativity self-efficacy beliefs' and technology specific 'positive affect in the context of digital innovations', rather than primarily relying on general traits or capabilities. In this context, it is prudent to also evaluate aspects of technology framing of innovative agent and technology related strain perceptions as a means to tease out the technology constraints. It is possible that such constraints may negatively influence innovation affordance and consequently digital innovation. However, more research on this aspect is useful before drawing such conclusions. Fourth, the results of the study are practically useful in understanding as to what extent of design-thinking creative process use can facilitate social and digital innovation amongst young adults. The pervasive use of technologies by digital natives [67] provides evidence that even without the structured use of a specific enterprise or group level creative support systems mandated from top down innovation governance entities, there could be the emergence of 
innovation affordances. Therefore, design-thinking approach may be a useful creative process that can be applied to all types of innovation contexts including those that are geographically distributed and rely on open innovation. Another related implication for practitioners and also for future researchers is to develop a configurational approach to the digital innovation process [68]. A configurational perspective to digital innovation will allow experimentation of different user profiles in conjunction with suitable environmental factors for specific problem types. Configurations can comprise a combination of factors such as innovation agent capabilities, suitable technological infrastructure, supportive environment, and a congruent problemsolving situation. Research on a successful typology of such profiles or configurational perspective on digital innovation is lacking thus far. In the present study, the problem that required a creative solution was an open ended and unstructured one that was externally driven to produce digital innovation. This is different from most actual situations in the organizations that may warrant a responsive creativity (to a specific problem) and is based on close ended creative problems that are structured and often produced by organizational think tanks [69]. Though this is a limitation of our study, future research can use our work to further explore this important aspect. In addition to this limitation, we acknowledge that the extent of digital innovation may also be influenced by the individual's perception of other team members' creative efficacy and also his/her affect towards other team members. Such factors can also be examined by future research. Although, we conducted a survey based quasi-experimental study, future research could design and conduct an actual experiment where the variables of interest could be suitable manipulated to provide robust results.

\section{References}

[1] Fichman, R.G., B.L. Dos Santos, and Z. Zheng, "Digital Innovation as a Fundamental and Powerful Concept in the Information Systems Curriculum", MIS Quarterly, 38, 2 (2014), pp. 329-253.

[2] Mithas, S. Digital Intelligence: What Every Smart Manager Must Have for Success in an Information Age, Penguin, UK, (2016).

[3] Barrett, M., L. Heracleous, and G. Walsham, “A Rhetorical Approach to IT Diffusion: Reconceptualizing the Ideology-Framing
Relationship in Computerization Movements" MIS Quarterly, 37, 1 (2013), pp. 201-220.

[4] Yoo, Y., R.J. Boland Jr, K. Lyytinen, and A. Majchrzak, "Organizing for Innovation in the Digitized World", Organization Science, 23, 5 (2012), pp. 1398-1408.

[5] Lyytinen, K., Y. Yoo, and R.J. Boland Jr, "Digital Product Innovation within Four Classes of Innovation Networks", Information Systems Journal, 26, 1 (2016), pp. 47-75.

[6] Nambisan, S., K. Lyytinen, A. Majchrzak, and M. Song, "Digital Innovation Management: Reinventing Innovation Management Research in a Digital Work”, MIS Quarterly, 41, 1 (2017), pp. 223-238.

[7] Livingstone, L.P., and D.L. Nelson, "PersonEnvironment Fit and Creativity: An Examination of Supply-Value and Demand-Ability Versions of Fit", Journal of Management, 23, 2 (1997), pp. 119-146.

[8] Withagena, R. and J.V.D. Kampb, "An Ecological Approach to Creativity in Making", New Ideas in Psychology, 49, (2018), pp. 1-6.

[9] Lubart, T, "Connecting Learning, Individual Differences and Creativity", Learning and Individual Differences, 18, 4(2008), pp. 361-362.

[10] Lubart, T. and J.-H. Guignard, "The GeneralitySpecificity of Creativity: A Multivariate Approach. Creativity: From Potential to Realization", In R. J. Sternberg, E. L. Grigorenko and J. L. Singer, Washington, DC, US, American Psychological Association, (2004), pp. 43-56

[11] Massetti, B, “An Empirical Examination of the Value of Creativity Support Systems on Idea Generation”, MIS Quarterly, 20, 3 (1996), pp. 8397.

[12] Wierenga, B. and G. H. van Bruggen, "The dependent variable in research into the effects of creativity support systems: Quality and Quantity of Ideas", MIS Quarterly, 22, 1 (1998), pp. 81-87.

[13] Johansson-Sköldberg, U., J. Woodilla, and M. Çetinkaya, "Design-Thinking: Past, Present and Possible Futures", Creativity and Innovation Management, 22, 2 (2013), pp.121-146.

[14] Glen, R., C. Suciu, and C. Baughn, "The Need for Design-Thinking in Business Schools", Academy of Management Learning \& Education, 13, 4 (2014), pp. 653-667.

[15] Elsbach, K.D. and I. Stigliani, "Design-thinking and Organizational Culture: A Review and Framework for Future Research", Journal of Management, 44, 6 (2018), pp. 2274-2306.

[16] Plattner, H., and C. Meinel, Design-thinking. Landsberg am Lech, Mi-Fachverlag, (2009). 
[17] Pozzi, G., F. Pigni, and Vitari, C. "Affordance Theory in the IS Discipline: A Review and Synthesis of the Literature." $20^{\text {th }}$ AMCIS, Savanah, U.S.A. (2014).

[18] Tierney, P. and S.M. Farmer "Creative Self-Efficacy Development and Creative Performance over Time", Journal of Applied Psychology, 96, 2, (2011), pp. 277-293.

[19] Zhang, P. "The Affective Response Model: A Theoretical Framework of Affective Concepts and their Relationships in the ICT Context", MIS Quarterly, 37, 1 (2013), pp. 247-274.

[20] Bandura, A. "Self-Efficacy: Toward a Unifying Theory of Behavioral Change," Psychological Review, 84, 2 (1977), pp. 191-215.

[21] Bandura, A. "Self-Efficacy Mechanism in Human Agency", American Psychologist, 37, 2, (1982), pp. 122-147.

[22] Choi, J.N. "Individual and Contextual Predictors of Creative Performance: The Mediating Role of Psychological Processes", Creativity Research Journal, 16 (2004), pp. 187-199.

[23] Malik, M.A.R., A.N. Butt, and J.N. Choi, "Rewards and Employee Creative Performance: Moderating Effects of Creative Self-Efficacy, Reward Importance, and Locus of Control", Journal of Organizational Behavior, 36 (2015), pp. 59-74.

[24] Tierney, P. and S.M. Farmer (2002). "Creative selfefficacy: Its potential antecedents and relationship to creative performance." Academy of Management journal 45(6): 1137-1148

[25] Tierney, P., S.M. Farmer, and G.B. Graen, "An Examination of Leadership and Employee Creativity: The Relevance of Traits and Relationships", Personnel Psychology, 52, 3 (2006), pp. 591-620.

[26] Gong, Y., J. C. Huang, and J.L. Farh, "Employee Learning Orientation, Transformational Leadership, and Employee Creativity: The Mediating Role of Employee Creative Self-Efficacy", Academy of Management Journal, 52, 4(2009), pp. 765-778.

[27] Lim, H. S. and J. N. Choi, "Testing an Alternative Relationship between Individual and Contextual Predictors of Creative Performance." Social Behavior and Personality: An International Journal, 37 (2009), pp. 117-135.

[28] Koenig-Lewis, N. and A. Palmer, "The Effects of Anticipatory Emotions on Service Satisfaction and Behavioral Intention", Journal of Services Marketing, 28, 6 (2014), pp. 437-451.

[29] Kubicek, B., E. Hoelzl, and C. Korunka, "Emotion Regulation Requirements and Affective Forecasts Regarding Expected Organizational Changes", Horiz. Psychol, 22, (2013), pp. 1-13.
[30] Richard, R., J. van der Pligt, and N. de Vries, "Anticipated Affect and Behavioral Choice", Basic \& Applied Social Psychology, 18 (1996), pp.111129.

[31] Kiviniemi, M.T. and K.M. Duangdao, "Affective Associations Mediate the Influence of Cost-Benefit Beliefs on Fruit and Vegetable Consumption", Appetite, 53, 3 (2009), pp. 771-775.

[32] Thompson, R.L., C.A. Higgins, and J.M. Howell, "Personal Computing toward a Conceptual Model of Utilization ", MIS Quarterly, 15, 1(1991), pp. 125136.

[33] Da Costa, C.G., Q. Zhou, and A. Ferreira, "The Impact of Anger on Creative Process Engagement: The Role of Social Contexts", Journal of Organizational Behavior: 39,4, (2018), pp. 495-506.

[34] Ashkanasy, N.M. and A.D. Dorris "Emotions in the Workplace", Annual Review of Organizational Psychology and Organizational Behavior, 4 (2017), pp. 67-90.

[35] Ford, C.M. "A Theory of Individual Creative Action in Multiple Social Domains", Academy of Management Review, 21 (1996), pp. 1112-1142.

[36] George, J.M. and J. Zhou, "Understanding When Bad Moods Foster Creativity and Good Ones Don't: The Role of Context and Clarity of Feelings", Journal of Applied Psychology, 87, 4 (2002), pp. 687-697.

[37] George, J.M. and J. Zhou, "Dual Tuning in a Supportive Context: Joint Contributions of Positive Mood, Negative Mood, and Supervisory Behaviors to Employee Creativity", Academy of Management Journal, 50, 3 (2007), pp. 605-622.

[38] Diliello, T.C., J.D. Houghton, and D. Dawley, "Narrowing the Creativity Gap: The Moderating Effects of Perceived Support for Creativity", The Journal of Psychology, 145, 3 (2011), pp. 151-172.

[39] Majchrzak, A. and M.L. Markus, Technology Affordances and Constraints Theory (of MIS) Encyclopedia of Management Theory. E. Kessler. Thousand Oaks, CA, Sage, (2014), pp. 832-836.

[40] Lubart, T. "How Can Computers Be Partners in the Creative Process: Classification and Commentary on the Special Issue", International Journal of Human-Computer Studies, 63, 4 (2005), pp. 365369.

[41] Burkhardt, J.M. and T. Lubart, "Creativity in the Age of Emerging Technology: Some Issues and Perspectives." Creativity and innovation Management, 19, 2 (2010), pp. 160-166. 
[42] Pickering, A., (Ed.) The Mangle of Practice: Time, Agency, and Science, University of Chicago Press, (2010).

[43] Orlikowski, W.J., "Sociomaterial Practices: Exploring Technology at Work." Organization Studies, 28, 9 (2007), pp. 1435-1448.

[44] Oldham, G. R. and N. Da Silva "The Impact of Digital Technology on the Generation and Implementation of Creative Ideas in the Workplace", Computers in Human Behavior, 42, (2015), pp. 5-11.

[45] Ryan, R.M. and E.L. Deci "Intrinsic and Extrinsic Motivations: Classic Definitions and New Directions." Contemporary Educational Psychology, 25, 1 (2000), pp. 54-67.

[46] Bandura, A. "Social Cognitive Theory: An Agentic Perspective." Annual Review of Psychology, 52, 1 (2001), pp. 1-26.

[47] Osburn, H.K. and M.D. Mumford "Creativity and Planning: Training Interventions to Develop Creative Problem-Solving Skills." Creativity Research Journal, 18, 2 (2006), pp. 173-190.

[48] Amabile, T.M. "The Social Psychology of Creativity: A Componential Conceptualization", Journal of Personality and Social Psychology, 45, 2, (1983), pp. 357-376.

[49] Parnes, S.J. and R.B. Noller "Applied Creativity: The Creative Studies Project: Part Results of a Two Year Program", Journal of Creative Behavior, 6 (1972), pp. 164-186.

[50] Sternberg, R. J. "Toward a Unified Theory of Human Reasoning", Intelligence, 10 (1986), pp. 281-314.

[51] Oldham, G.R. and A. Cummings, "Employee Creativity: Personal and Contextual Factors at Work", Academy of Management Journal, 39, 3, (1996), pp. 607-634.

[52] Baccardini, D. "The Concept of Project Complexity: A Review", International Journal of Project Management, 14, 4 (1996), pp. 201-204.

[53] Tarafdar, M., Q. Tu, and T.S. Raghunathan, "Impact of Technostress on End-User Satisfaction and Performance", Journal of Management Information Systems, 27, 3 (2010), pp. 303-334.

[54] Ringle, C. M., and S. Wende, SmartPLS 2.0 (M3) Beta. Hamburg (2005), SmartPLS.

[55] Fornell, C. and D. Lacker "Evaluating Structural Equation Models With Unobservable Variables and Measurement Error", Journal of Marketing Research, 18, 1 (1981), pp. 39-50.

[56] Wold Partial Least Squares. Encyclopedia of Statistical Sciences (6), Wiley, New York, (1985).
[57] Hair, J.F., W.C. Black, et al., Eds., Multivariate Data Analysis Upper Saddle River, NJ, Prentice Hall, (1998).

[58] Straub, D., M.C. Boudreau, and D. Gefen, "Validation Guidelines for IS Positivist Research", Communications of the Association for Information Systems, 13 (2004), pp. 380-427.

[59] Petter, S., D.W. Straub, and A. Rai, "Specifying Formative Constructs in Information Systems Research", Management Information Systems Quarterly, 31, 4 (2007), pp. 623-656.

[60] Chin, W.W. The Partial Least Squares Approach For Structural Equation Modelling. Modern Methods for Business Research. G. A. Marcoulides. Mahwah, New Jersey, Lawrence Erlbaum, (1998).

[61] Hair, J.F., G.T.M. Hult, CM Ringle, M Sarstedt, "Mirror, Mirror on the Wall: A Comparative Valuation of Composite-Based Structural Equation Modeling Methods", Journal of the Academy of Marketing Science, 45, 5 (2017), pp. 616-632.

[62] Financial Brand "Design-Thinking: The Hottest New Trend in Banking." Retrieved 06 June 2018, from https://thefinancialbrand.com/70152/designthinking-banking-financial-innovation/

[63] Brown, T. Change by Design. Harper Collins, New York, (2010).

[64] Carlgren, L., I. Rauth, and M Elmquist, "Framing Design-Thinking: The Concept in Idea and Enactment", Creativity and Innovation Management, 25, 1 (2016), pp. 38-57.

[65] Stone, M. "Cross-Validatory Choice and Assessment of Statistical Predictions", Journal of the Royal Statistical Society, 36, 2 (1974), pp. 111147.

[66] Geisser, S. "A Predictive Approach to the Random Effects Model." Biometrika 61, 1 (1974), pp. 101107.

[67] Shirish, A., I. Boughzala, and S.C. Srivastava, "Adaptive Use of Social Networking Applications in Contemporary Organizations: Examining the Motivations of Gen Y Cohorts", International Journal of Information Management, 36, 6 (2016), pp. 1111-1123.

[68] Isaksen, S.G., G.J. Puccio, and D.J Treffinger, “An Ecological Approach to Creativity Research: Profiling For Creative Problem Solving", The Journal of Creative Behavior, 27, 3 (1993), pp. 149170.

[69] Unsworth, K. "Unpacking Creativity." Academy of Management Review, 26, 2 (2001), pp. 89-97. 


\section{Appendix 1:}

ICT enabled design thinking creative process

(Measured on a 7 point Likert scale ranging from strongly agree to strongly disagree).

To what extent did you use information communication technologies for the activities listed below (Please note the term 'users' in the statements below includes any human/ virtual entity (for example a customers, consumer, stakeholders or society) relevant to the problem.
1. To observe the behaviors and perceptions of the problem impacted user group (DT1)

2. To define potential solutions to the problem (DT2)

3. To enable brainstorming of the creative solutions with others (DT3)

4. To develop a prototype inorder to get quick reaction and user feedback (DT4)

5. To iterate and devise a final solution, service or product for the identified problem (DT5) 